\section{Skin tissue expression and serum level of thymic stromal lymphopoietin in patients with psoriasis vulgaris}

\author{
Oki Suwarsa, Hartati Purbo Dharmadji, \\ Endang Sutedja, Lengga Herlina, \\ Putri Reno Sori, Reti Hindritiani, \\ Reiva Farah Dwiyana, \\ Hendra Gunawan \\ Department of Dermatology and \\ Venereology, Faculty of Medicine, \\ Universitas Padjadjaran; Hasan Sadikin \\ General Hospital, Bandung, West Java, \\ Indonesia
}

\begin{abstract}
Thymic stromal lymphopoietin (TSLP) is known to be associated with allergic diseases. It is also suggested that TSLP has a role in autoimmune diseases such as psoriasis; however, the associated pathways remain unknown. There is currently little information on TSLP in psoriasis vulgaris. We investigated TSLP expressions on lesional and non-lesional skin of psoriasis vulgaris patients using reverse transcription-polymerase chain reaction. TSLP level was also investigated in serum from psoriasis vulgaris patients compared to healthy control using enzyme-linked immunosorbent assay. TSLP expression was higher in lesional skin (1.90) compared to non-lesional skin (1.76); however, the difference was not statistically significant $(\mathrm{P}>0.05)$. TSLP serum levels were significantly higher in psoriasis patients $(287.40 \mathrm{pg} / \mathrm{dL})$ as compared to controls $(114.70 \mathrm{pg} / \mathrm{dL})(\mathrm{P}<0.05)$. This study concluded that TSLP levels in the serum of psoriasis vulgaris patients are higher than controls. TSLP was also found in keratinocyte of psoriasis patients, the expression was higher in the lesional compared to non-lesional skin; however, this difference is statistically insignificant. These findings suggest that TSLP may play a role in the pathogenesis of psoriasis vulgaris, but its exact role remains unclear.
\end{abstract}

\section{Introduction}

Psoriasis is a chronic inflammatory skin disease, with a strong genetic basis, characterized by complex alterations in epidermal growth and differentiation, as well as multiple biochemical, immunologic, and vascular abnormalities. ${ }^{1}$ The pathogenesis of this disease is linked to many interactive responses among infiltrating white blood cells, dendritic cells, proinflammatory cytokines, chemokines, and chemical mediators produced in the skin. ${ }^{2}$ Nowadays, it is believed that psoriasis is most likely a $\mathrm{T}$ helper-1 (Th1)/ Th17 induced inflammatory disease. ${ }^{3}$ Thymic stromal lymphopoietin (TSLP) or interleukin (IL)-7-like cytokine has already been associated with atopic dermatitis for its role in inducing a proallergic Th2 response. ${ }^{4}$ The associated pathways of TSLP in psoriasis remains unknown. There is currently little information on TSLP in psoriasis vulgaris patients. ${ }^{5}$ In this study, we report the skin tissue expressions on lesional and non-lesional skin and serum level of TSLP of psoriasis vulgaris patients.

\section{Materials and Methods}

\section{Patients}

The study was performed in accordance with the ethical guidelines in the Declaration of Helsinki and was approved by the Health Research Ethics Committee of Hasan Sadikin General Hospital, Bandung, West Java, Indonesia. Oral explanation was given about the study and written informed consent was subsequently obtained from each participant.

Seventeen subjects for psoriasis vulgaris group and 17 subjects for control group were recruited from the Dermatology Clinic at Hasan Sadikin General Hospital using a consecutive sampling technique. Exclusion criteria include patients who had systemic and/or topical corticosteroids, antibiotics, and other immunosuppressive agents, such as cyclosporine, methotrexate, azathioprine within the last two weeks prior to the start of the study, as well as history of atopic manifestations, infections, and malignancies.

\section{Reverse transcription-polymerase chain reaction for thymic stromal} lymphopoietin expression in skin

After obtaining informed consent from patients, $2.5-\mathrm{mm}$ punch skin biopsy specimens were taken from lesional and nonlesional skin in psoriasis vulgaris patients. Skin samples were collected in Eppendrof tube and immediately stored at $-2^{\circ} \mathrm{C}$ temperatures. TSLP transcript expression was analyzed on ribonucleic acid (RNA) extracted from homogenized skin and reverse transcribed using standard protocols. Deoxyribonucleic acid (DNA) was analyzed for the expression of human glyceraldehyde-3-phosphate dehydrogenase (GAPDH; forward, ATCAGCAATGCCTC-
Correspondence: Oki Suwarsa, Department of Dermatology and Venereology, Faculty of Medicine, Universitas Padjadjaran; Hasan Sadikin General Hospital, Jl. Pasteur No. 38, Bandung, West Java, 40161, Indonesia.

Tel.: +62.22.2032426 (ext. 3449) -

Fax: +62.22.2032426.

E-mail: oki.suwarsa@unpad.ac.id

Key words: Psoriasis vulgaris; Serum; Skin; Thymic stromal lymphopoietin.

Acknowledgments: the authors would like to thank the contribution of Health Research Unit, Universitas Padjadjaran, Bandung, West Java, Indonesia, for technical assistance.

Contributions: the authors contributed equally.

Conflict of interest: the authors declare no potential conflict of interest.

Funding: the work was support by an internal grant of Universitas Padjadjaran, Bandung, West Java, Indonesia (Grant No 2476/UN6C/LT/2018)

Received for publication: 1 February 2019.

Revision received: 10 May 2019.

Accepted for publication: 13 May 2019

This work is licensed under a Creative Commons Attribution-NonCommercial 4.0 International License (CC BY-NC 4.0).

(C) Copyright O. Suwarsa et al., 2019

Licensee PAGEPress, Italy

Dermatology Reports 2019; 11:8006

doi:10.4081/dr.2019.8006

CTGCAC; reverse, TGGCATGGA CTGTGGTCATG) and TSLP (forward, CACCGTCTCT TGTAGCAATCG; reverse, TAGCCT GGGCACCAGATAGC) using Rotor-Gen-Q.

\section{Enzyme-linked immunosorbent} assay for thymic stromal lymphopoietin level in serum

Approximately $5 \mathrm{~mL}$ of blood were collected in a tube without heparin from patients and participants in the control group. Healthy age- and sex-matched control subjects were also included in the study. TSLP were measured using enzyme-linked immunosorbent assay (ELISA) kit, according to the manufacturer's instructions (Cloud-Clone Corp, Houston, USA). TSLP level $(\mathrm{pg} / \mathrm{mL})$ were used for data analysis.

\section{Statistical analysis}

This study was an observational study, using a cross-sectional method to determine TSLP levels in the serum of psoriasis vulgaris patient and healthy control, as well as TSLP expression in lesions and non-lesions 
skin of psoriasis vulgaris patients. Statistical significance was retained for Pvalues of less than 0.05 .

\section{Results}

\section{Demographic details}

Seventeen subjects from each group were reviewed and analyzed descriptively. Patients with psoriasis vulgaris included 13 males and 4 females, with age ranges between 10 and 68 years old (Table 1). The healthy control group with no complaint of any dermatological disorder comprised of 13 males and 4 females, their age ranges between 12 and 67 years old.

\section{Psoriasis area severity index}

Psoriasis area severity index was used to assess the degree of severity of disease in this study. In general, $58.8 \%$ of participants in this study had a mild form of the disease.

\section{Thymic stromal lymphopoietin expression in psoriasis skin}

We analyzed the expression of TSLP in lesional and non-lesional psoriasis skin. Samples from 17 patients were assessed and were all positive for TSLP (Table 1). As shown in Table 2, the lesional skin (medi$\mathrm{an}=1.90$; range $=1.51-2.21$ ) showed elevation of TSLP expression compared to nonlesional skin (median $=1.76$; range $=1.66$ 2.17). Statistical analysis showed that the difference between TSLP expression in lesional and non-lesional skin of psoriasis patients was statistically insignificant $(\mathrm{P}>0.05)$.

\section{Thymic stromal lymphopoietin serum level}

To determine whether TSLP could be involved in pathogenesis psoriasis vulgaris, we analyzed the serum level of TSLP in psoriasis vulgaris patients and normal controls. Sample from 17 patients and 17 controls were assessed (Table 1). TSLP serum levels in subjects with psoriasis vulgaris patients (median $=286.30 \quad \mathrm{pg} / \mathrm{mL}$; range $=71.90-695.1 \mathrm{pg} / \mathrm{mL}$ ) were significantly higher than normal controls (median $=114.70 \quad \mathrm{pg} / \mathrm{mL} ; \quad$ range $=50.0-206.1$ $\mathrm{pg} / \mathrm{mL})(\mathrm{P}<0.05)$ (Table 3).

\section{Discussion}

TSLP is a cytokine expressed mainly in the epithelial cells of the lungs, gastrointestinal tract, thymus, tonsils, and epidermal keratinocytes. ${ }^{6}$ TSLP will bind to the $\alpha$-chain IL-7 receptors (IL-7R $\alpha$ ) and TSLP receptor (TSLPR), ${ }^{6,7}$ which are expressed in various hematopoietic cells, such as in dendritic cells, T cells, B cells, mast cells, and macrophages. ${ }^{6}$

TSLP has been associated with atopic dermatitis, ${ }^{8}$ asthma, ${ }^{9,10}$ and allergic rhinitis ${ }^{8}$ for its role in inducing a proallergic Th2 response. ${ }^{8}$ Here we report that TSLP is also produced in patients with psoriasis vulgaris, a Th1-related autoimmune disease. Our findings add to the existing complexity of the cytokine and inflammatory networks in patients with psoriasis and suggest that TSLP might have different immunomodulatory roles, depending on the type of inflammatory environment. In addition, it can also explain that one cytokine may have different functions.

In the pathogenesis of psoriasis, when precipitating factors from the environment were exposed to a person with genetic predisposition, this will cause keratinocytes to release IL-1 and TNF- $\alpha$ cytokines which will induce dendritic cells in the skin as antigen presenting cell. It is also known that keratinocytes in psoriasis patients express TSLP that bind to TSLPR and IL-7R $\alpha$ receptors in dendritic cells. ${ }^{5}$ Maturation of dendritic cells will produce cytokines such as IL-12 and IL-23 which will induce differentiation of naive $\mathrm{T}$ cells into Th1/Th17 cells. Th1/Th17 cell differentiation will result in the secretion of cytokines that contribute to keratinocyte proliferation and inflammatory responses. ${ }^{4}$

In our study, TSLP was observed in serum and skin of psoriasis patients, indicating that their production and function are linked to the pathogenesis of the disease. The current study shows that TSLP is produced by keratinocytes in patients with psoriasis and that TSLP, in this context, primes for IL-23 production by dendritic cells. ${ }^{5}$

Table 1. Thymic stromal lymphopoietin expression in serum and skin biopsy specimens from patients with psoriasis.

\begin{tabular}{|c|c|c|c|c|c|c|c|}
\hline No. & Sex & Age (y) & PASI score & $\begin{array}{c}\text { TSLP in serum } \\
\text { psoriasis }(\mathrm{pg} / \mathrm{mL})\end{array}$ & $\begin{array}{l}\text { TSLP in serum } \\
\text { control }(\mathrm{pg} / \mathrm{mL})\end{array}$ & $\begin{array}{l}\text { TSLP in } \\
\text { lesional }\end{array}$ & $\begin{array}{c}\text { TSLP in } \\
\text { non-lesional }\end{array}$ \\
\hline A & $\mathrm{F}$ & 31 & 10.2 & 359.1 & 204.3 & 2.05 & 1.71 \\
\hline B & M & 48 & 8.4 & 223.6 & 149.9 & 1.90 & 1.92 \\
\hline $\mathrm{C}$ & M & 28 & 18.7 & 215.9 & 58.1 & 1.95 & 1.76 \\
\hline D & M & 45 & 2.7 & 286.3 & 153.4 & 2.03 & 1.80 \\
\hline$E$ & M & 56 & 2.6 & 288.5 & 74.7 & 2.06 & 1.73 \\
\hline $\mathrm{F}$ & $\mathrm{F}$ & 51 & 2 & 338.3 & 144.7 & 1.90 & 1.67 \\
\hline $\mathrm{G}$ & M & 42 & 2.7 & 279.1 & 79.3 & 1.57 & 1.72 \\
\hline $\mathrm{H}$ & M & 24 & 3 & 209.6 & 122.4 & 1.86 & 1.72 \\
\hline I & M & 62 & 15.7 & 260.1 & 69.9 & 1.70 & 1.70 \\
\hline $\mathrm{J}$ & $\mathrm{F}$ & 64 & 4.3 & 149.2 & 68.8 & 1.89 & 1.66 \\
\hline K & M & 37 & 6.2 & 505.8 & 204.8 & 2.21 & 1.87 \\
\hline L & M & 49 & 9.9 & 438.0 & 206.1 & 1.67 & 1.83 \\
\hline M & M & 43 & 13.9 & 695.1 & 50.0 & 1.83 & 1.75 \\
\hline $\mathrm{N}$ & $\mathrm{F}$ & 20 & 2.1 & 643.7 & 155.4 & 1.51 & 2.17 \\
\hline 0 & M & 10 & 3.3 & 292.2 & 90.0 & 1.78 & 2.15 \\
\hline $\mathrm{P}$ & M & 68 & 10.6 & 544.0 & 160.2 & 1.95 & 2.01 \\
\hline Q & $\mathrm{M}$ & 52 & 3.0 & 179.0 & 149.9 & 2.05 & 1.83 \\
\hline
\end{tabular}

PASI, Psoriasis Area Severity Index; TSLP, thymic stromal lymphopoietin; F, female; M, male. 
From a pathological perspective, it will be important to establish the links between TSLP and other cytokines involved in pathogenic inflammatory networks in patients with diverse autoimmune diseases. In patients with psoriasis, TSLP could serve as a therapeutic target to reduce dendritic cell activation and production of pathogenic IL$23 .{ }^{4}$ This study also found that the difference in TSLP expression in lesional and non-lesional skin was insignificant. Several factors that can affect the result in various studies on cytokine levels include different standardization, reagent sensitivity, examination material, sample handling, and various biological factors such as age, race, and genetic polymorphism. ${ }^{11}$ In 2010, Tindall et al. ${ }^{12}$ found genetic polymorphisms in the IL-23A gene in South African populations and European populations. In this study, 33 different DNA variations were identified, and the suspected functional variation of IL-23A will have a significant impact on the patient's immune response. To date, there is no data available that explains the existence of TSLP polymorphisms in psoriasis vulgaris. However, several researches have been conducted on Graves' disease. In 2012, Tsai et al. ${ }^{13}$ from Taiwan found TSLP polymorphisms in Graves' disease which can be used to estimate the prognosis and target therapy. The results yielded in this study were different from that of previous research conducted by Volpe et al. in 2014 in Paris. ${ }^{5}$ That study, TSLP were assessed with reverse transcription-polymerase chain reaction (RT-PCR), found that TSLP expression was higher in lesional than in non-lesional skin of psoriasis vulgaris patients and normal individuals. ${ }^{5}$ Genetic and environmental factors are thought to play a significant role in the pathogenesis of psoriasis vulgaris, due to the fact that these conditions often affect the results of psoriasis research, and yielded varying results in each country.

The limitation of this study was we could not investigate TSLP expression in normal skin control and the correlation between serum and skin TSLP directly. There was no report about serum TSLP level in previous studies. As TSLP is a circulating mediator, we assumed that there might be indirect correlation between serum and skin TSLP and further studies are required to obtain further knowledge on this correlation.

\section{Conclusions}

This study found that TSLP level in the serum of psoriasis vulgaris patients are higher than controls, while TSLP expression was higher in the lesional skin compared to the non-lesional skin of psoriasis vulgaris patients; however, this difference is statistically insignificant. These findings suggest that TSLP may play a role in the pathogenesis of psoriasis, but its exact role remains unknown.

Table 2. Thymic stromal lymphopoietin expression on lesional and non-lesional skin of psoriasis vulgaris patients.

\begin{tabular}{lccc}
\hline Variable & \multicolumn{2}{c}{ Group } & P-value* \\
TSLP & & & \\
Mean \pm Std & $1.87 \pm 0.186$ & $1.82 \pm 0.156$ & 0.234 \\
\hline Median & 1.90 & 1.76 & \\
Range (min-max) & $1.51-2.21$ & $1.66-2.17$ & \\
\hline
\end{tabular}

TSLP, thymic stromal lymphopoietin. ${ }^{*}$ P-value by Wilcoxon test analysis. Statistical significant was accepted at $\mathrm{P}<0.05$.

Table 3. Comparison of thymic stromal lymphopoietin serum level in psoriasis patients and control group.

\begin{tabular}{lccc} 
Variable & & Group & \\
& Psoriasis $n=17$ & Control $n=17$ & 0.000 \\
TSLP & & & \\
Mean \pm Std & $332.18 \pm 170.531$ & $121.11 \pm 53.501$ & \\
\hline Median & 286.30 & 114.70 & \\
Range (min-max) & $71.90-695.10$ & $50.00-206.10$ & \\
\hline
\end{tabular}

TSLP, thymic stromal lymphopoietin. ${ }^{*}$ P-value by t test analysis. Statistical significant was accepted at $\mathrm{P}<0.05$.

\section{References}

1. Gudjonsson JE, Elder JT. Psoriasis. In: Wolff K, Goldsmith LA, Katz SI, et al., eds. Fitzpatrick's dermatology in general medicine. 8th ed. New York: McGraw-Hill; 2012. pp 197-231.

2. Lowes MA, Bowcock AM, Krueger JG. Pathogenesis and therapy of psoriasis. Nature 2007;445:866-73.

3. Coimbra S, Figueiredo A, Castro E, et al. The roles of cells and cytokines in the pathogenesis of psoriasis. Int $\mathrm{J}$ Dermatol 2012;51:389-98.

4. Blauvelt A. New concept in the pathogenesis and treatment of psoriasis: key roles for IL-23, IL-17A and TGF- $\beta$. Expert Rev Dermatol 2007;2:69-75.

5. Volpe E, Pattarini L, MartinezCingolani C, et al. Thymic stromal lymphopoietin links keratinocytes and dendritic cell-derived IL-23 in 209 patients with psoriasis. J Allergy Clin Immunol 2014;134:373-81.

6. He R, Geha RS. Thymic stromal lymphopoietin. Ann Acad Sci 2010;1183: 13-24.

7. Ziegler SF, Roan F, Bell BD, et al. The biology of thymic stromal lymphopoietin (TSLP). Adv Pharmacol 2013;66:129-55.

8. Soumelis V, Reche P, Kanzler H, et al. Human epithelial cells trigger dendritic cell mediated allergic inflammation by producing TSLP. Nat Immunol 2002;3:673-80.

9. Zhou B, Comeau MR, De Smedt T, et al. Thymic stromal lymphopoietin as a key initiator of allergic airway inflammation in mice. Nat Immunol 2005;6:1047-53.

10. Al-Shami A, Spolski R, Kelly J, et al. A role for TSLP in the development of inflammation in an asthma model. J Exp Med 2005;202:829-39.

11. Banks RE. Measurements of cytokine in clinical samples using immunoassay: problem and pitfalls. J Rev Clin Lab Sci 2000;37:131-82.

12. Tindall EA, Hayes VM. Comprehensive sequence analysis of the human IL23A gene defines new variation content and high rate of evolutionary concervation. DNA Res 2010;17:117-22.

13. Tsai KH, Tsai FJ, Lin HJ, et al. Thymic stromal lymphopoietin gene promoter polymorphisms and expression levels in Graves disease and Graves ophtalmopathy. BMC Med Gen 2012;13:1-7. 